\title{
PRECARIOUS EMPLOYMENT IN RURAL ONTARIO
}

\section{Design it. Plan it.}



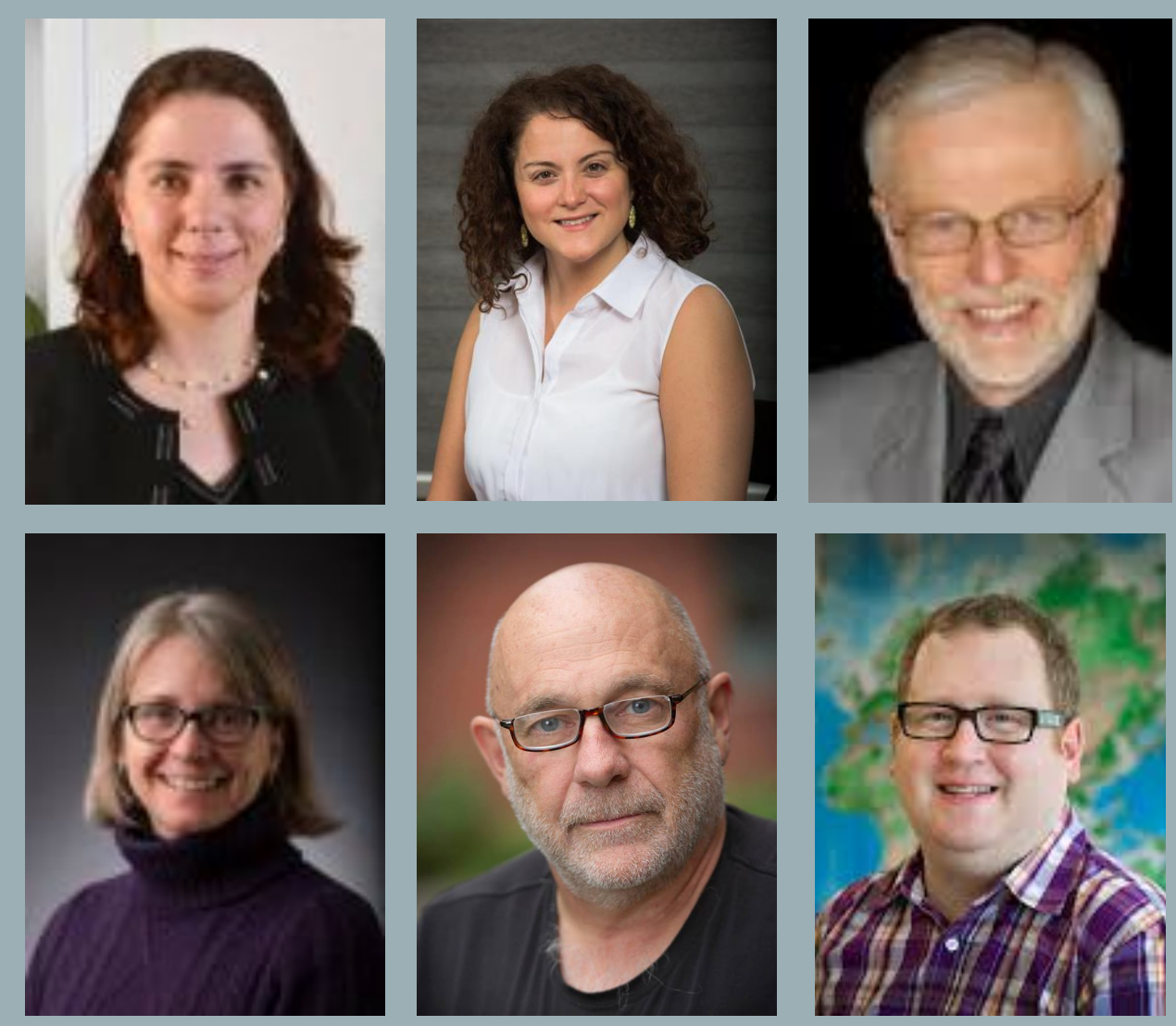

\section{THE RESEARCH TEAM}

Carol Kenny, OMAFRA, not pictured 


\section{OVERVIEW}

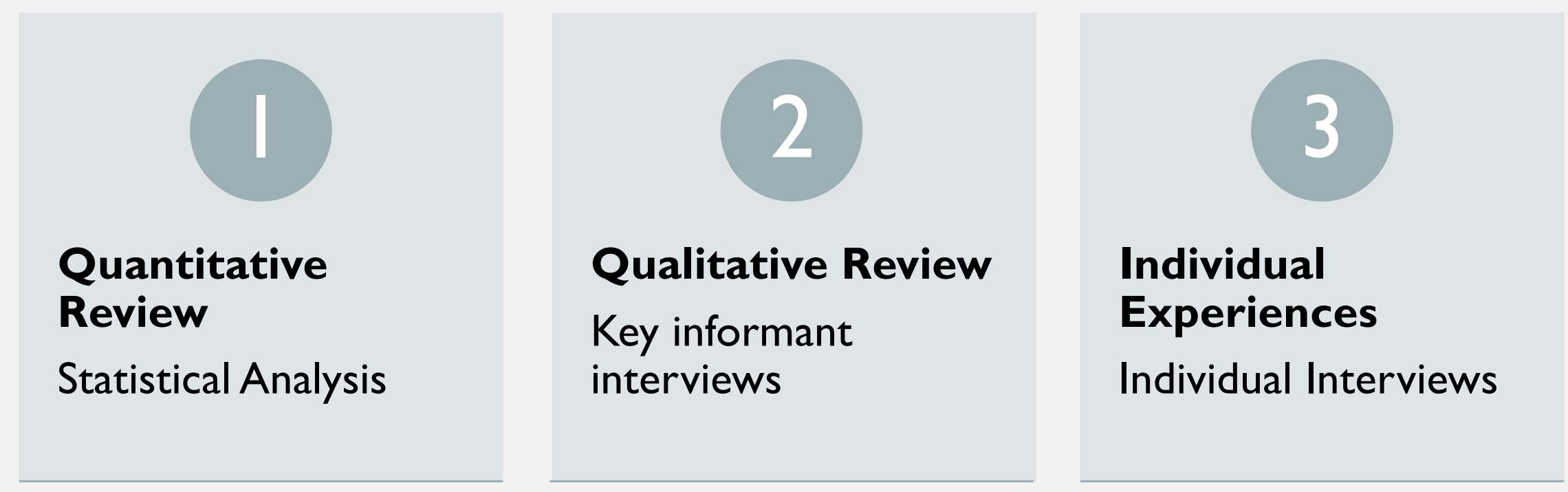

https://ruralprecariousemployment.wordpress.com/ 


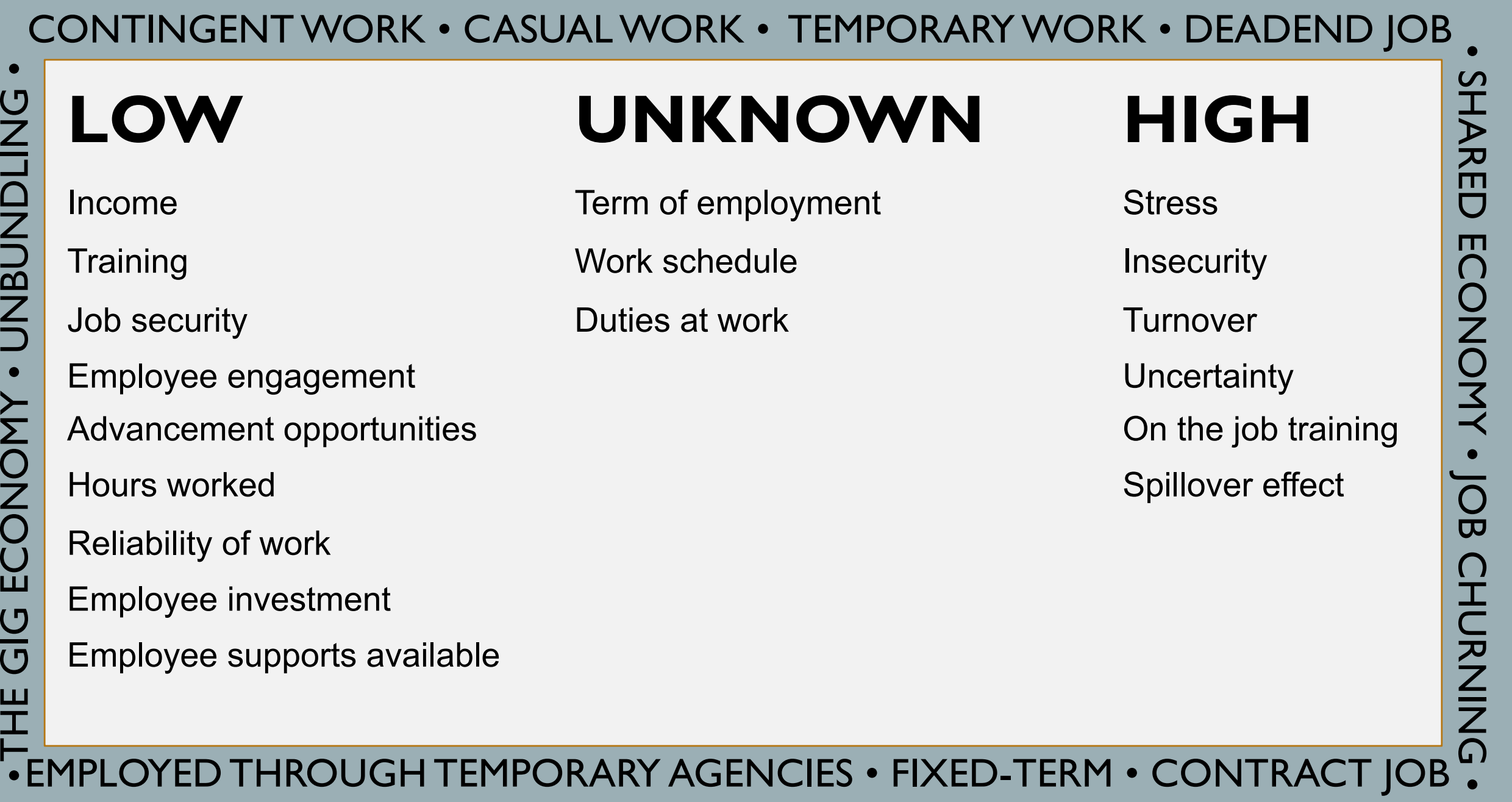




\section{INDICATORS}


FROM THE LITERATURE 
HEALTH

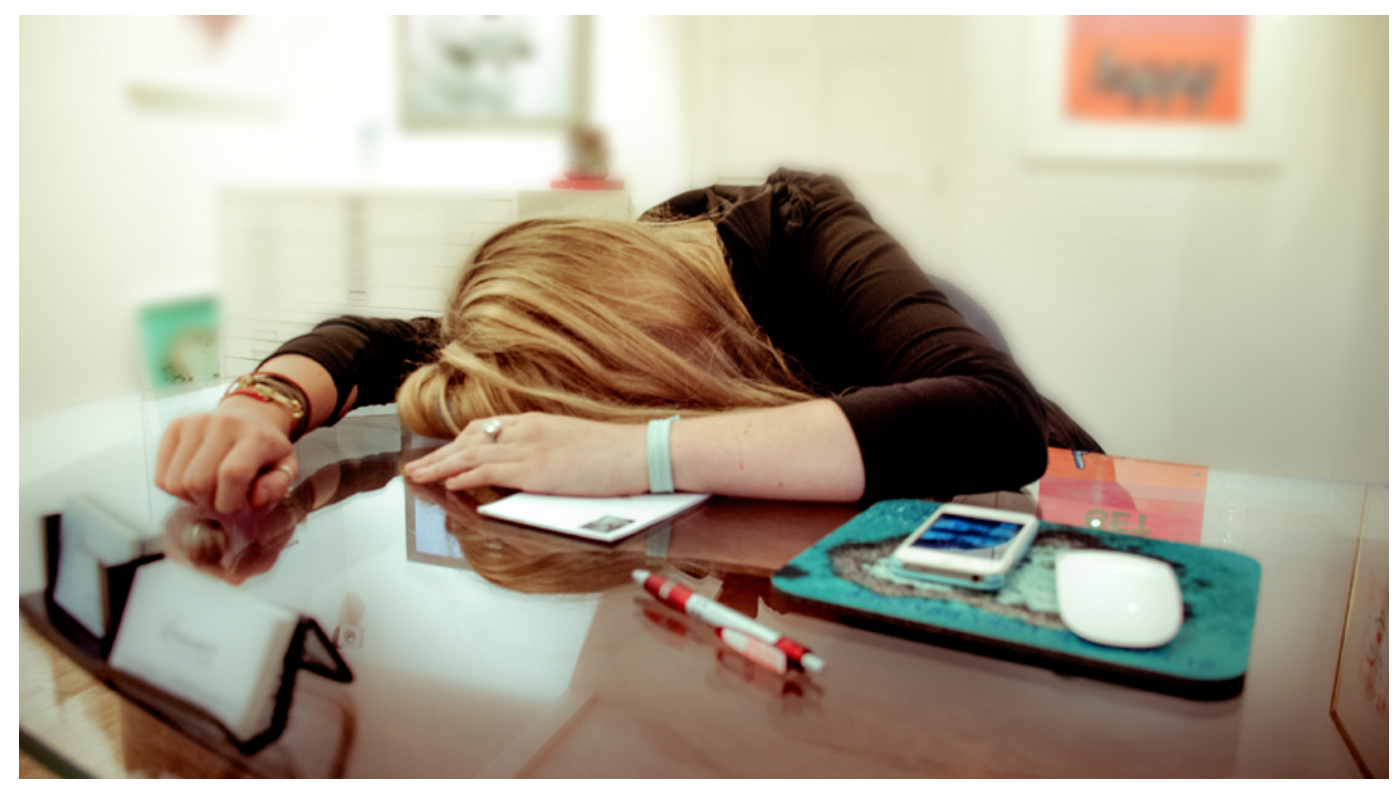



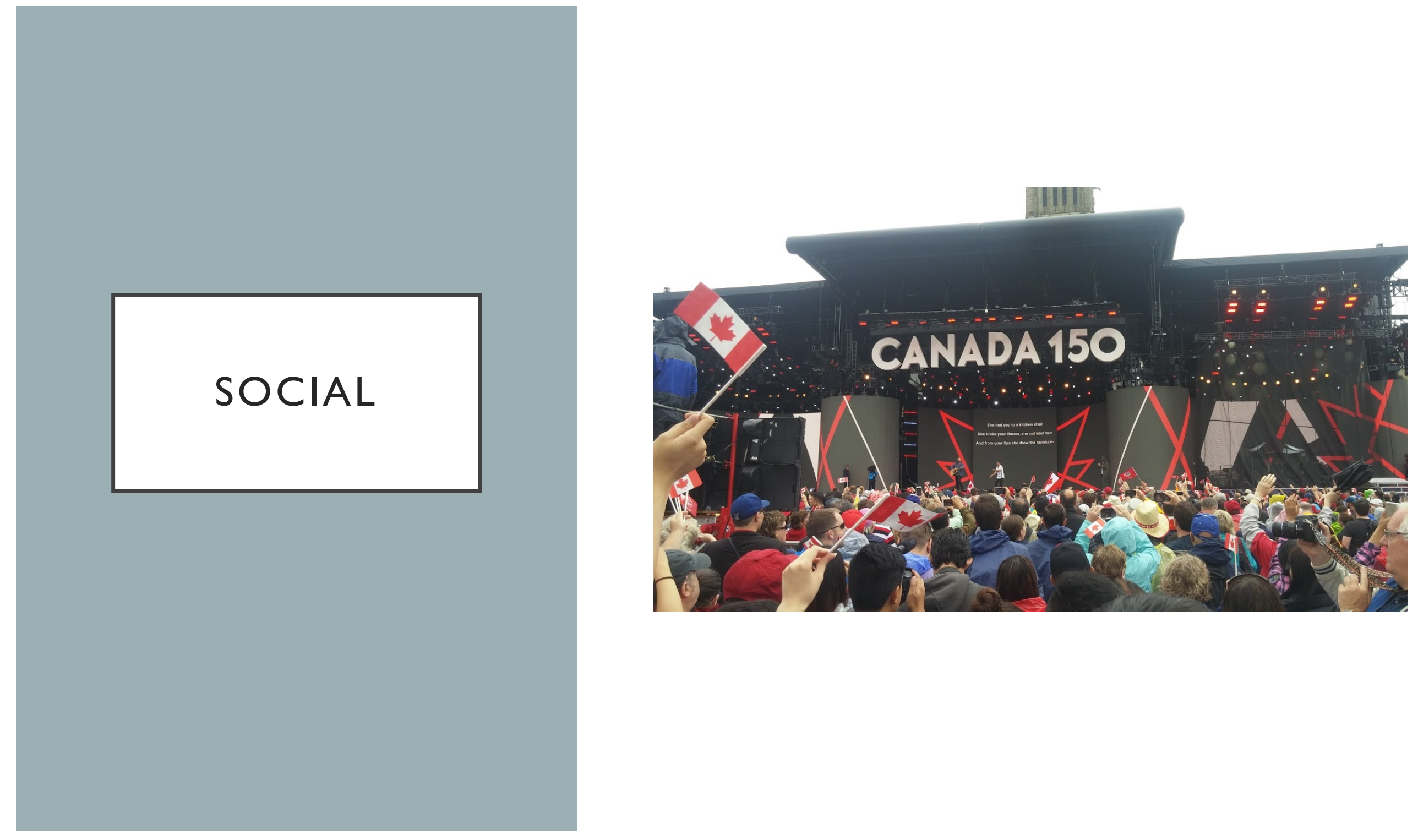

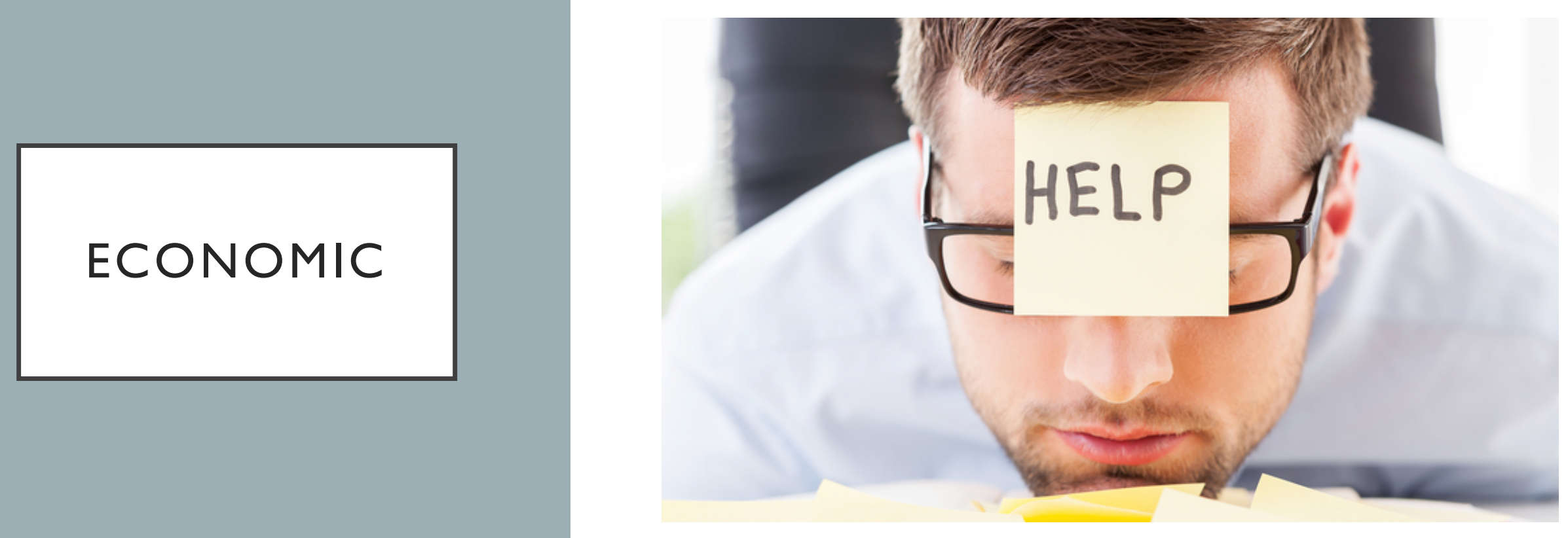
FROM THE FIELD 


\section{Employee}

- Stressful, feelings of inadequacy and negative self-view

- Not offered the same supports as the unemployed

- More difficult for older workers

- Unable to navigate job search system

- Job acquisition costs (medical testing, safety equipment) are at the cost of employees 


\section{Family}

- Compounding problem for families: cannot manage childcare, car use, relationships are strained

- Lack of permanency, unable to make future plans

- Increased stress levels (stress of keeping job, worried about losing job, stress of losing a job, stress of searching for a job)

- Lots of travel time to jobs in rural areas, especially if working multiple jobs, can be dangerous in winter, can be costly too 


\section{Thoughts...}

I think it's a systemic issue. We have employment support services funding through the ministry and they are geared for those furthest removed from the job market. Those with the most barriers, the most challenged, they get the services. But guess who is left in the middle? The person with an average level of education, they finished high school and may have a little post-secondary, maybe a little college, there is no support structure for those individuals, the perception is they are able to do all of this on their own and they have those skills (Interviewee 7). 
